\title{
Lignin as Natural Antioxidant Capacity
}

\author{
Zahed Mahmood, Muhammad Yameen, \\ Muhammad Jahangeer, Muhammad Riaz, \\ Abdul Ghaffar and Irum Javid
}

Additional information is available at the end of the chapter

http://dx.doi.org/10.5772/intechopen.73284

\begin{abstract}
Cell wall of various plants contains an organic polymer lignin. Lignin makes significant structural constituents that support of vascular plants tissues, some types of algae and makes plants stiff and woody. Chemically lignin composed of cross-linked phenolic polymers and Kraft lignin dissolved in the unsaturated resin system. Lignin is a vastly available and well-studied antioxidant. They work as antioxidant against the biological, chemical and mechanical stress on plants. The substance that removes potentially damaged oxidizing agents in a living organism is regarded as antioxidant. Lignin contains a huge amount of phenolic constructions that enable it to act as an effectual antioxidant. Infrared spectroscopy (IR) observed decreases in some oxidative aging products and maintained the idea that lignin play role as an effective antioxidant. It was discovered that antioxidant action of lignin varies with the molecular characteristics, isolation method and genetic origin. Capacity of lignin to scavenge the radicals that are involved in the oxidation is affected by partial dispersion into polymer matrix. Antioxidant activities of various technical lignins are determined. Chemical changes in lignin could result in products with characteristics that can be used in special industrial divisions.
\end{abstract}

Keywords: kraft lignin, lignin as antioxidant, cytotoxicity, application of lignin, phenolic polymers, sources of lignin, and isolation of lignin

\section{Introduction}

The term lignin is derivative from the Latin word lignum, meaning wood. It was initially separated from wood, described in a scientific description made by the French scientist Payen 1838, and later specified its modern name in 1857 by Schulze. Lignin was previously labeled as 
an incrusting of cellulose and this opinion is insightful as lignification happens after the deposition of polysaccharides. Simply stated, it is similar to the medium for a fiber reinforced compound. Lignin plays several different roles with the cell wall like modifying the permeability and temperature stability, but its principal role is to serve as a structural material which enhances the strength and rigidity to plants. Lignin differentiates lignocellulosic material from other materials rich in polysaccharide by strengthening the polysaccharide framework of the cell wall. Its presentation is very beneficent that it permits trees to compete other plants for sunlight creating the major creatures on this planet.

Lignin contains phenolic hydroxyl group also that makes it capable to play role in the food industry as strong antioxidant, avoid removing colour of food, taste and active vitamins concentration and molecules stabilization that are involved in these features. Oxidized lignin comprises properties which are associated to lignosulfonates and can be used in different industrial applications, mostly as dispersants and fillers. Kraft lignin from wood sources in pulp industry was stated to be as effective as vitamin $\mathrm{E}$ to shelter the oxidation of corn oil. The monomers degradation of lignin and their derivatives afforded high-quality antioxidant and anti-inflammatory characteristics. Additionally, lignin itself has been demonstrated to carry antimicrobial and insecticidal characteristics. The lignins of different botanical origins like annual plants, coniferous trees and deciduous trees were separated and fractionated by special types of different techniques included delignification by alkali, Kraft process, fast pyrolysis and hydrolysis. For characterization of antioxidant action of naturally present Phenolic compounds, a method using diphenyl picrylhydrazyl (DPPH) as a responsive free radical is now familiar as one that offers an opportunity to find radical scavenging ability. The antioxidant activities were determined as the capability to scavenge the DPPH $\bullet$ and $\left(2,2^{\prime}\right.$-azino-bis (3-ethylbenzothiazoline-6-sulphonic acid)) $\mathrm{ABTS}^{\bullet+}$ free radicals. The correlation between the structure of lignin and the antioxidant action was characterized by multivariate analysis, partial correlation, pair correlation, together with interrelated components regression.

Lignin constitutes $15-40 \%$ of dry weight of woody plants, it is highly present aromatic polymer on this planet and the second frequently present organic polymer after cellulose. Based on annual biomass growth rates, the overall production of lignin is $5.36 \times 108$ tons. That's why, lignin is a proved to be the fundamental source of aromatic compounds for the chemical industry, increasing after the conversion of modern age $\mathrm{CO}_{2}$, and its effective operation resolves a possible puzzle in generating useful byproducts in a biorefinery organization. This reasoning is because if wood is converted to billion-ton scale to produce biofuels and biochemicals, then there will be 300 million tons upwards of lignin potentially accessible. To put this in viewpoint it is hardly the size of a global polymer market.

The monomeric units are built into the macromolecular lignin from the oxidative radical coupling of these substructures [1]. Lignification is originated when the phenolic hydroxyl hydrogen is inattentive by the peroxidase enzyme to form a free radical of phenoxy, typically referred to as dehydrogenative polymerization. This phenoxy free radical will then delocalize to both aromatic and side chain carbon atoms through the process of resonance stabilization.

Development regarding lignin description in the nineteenth century donated to new materials development created upon renewable resources of lignin. Enhanced skills linked with processing of wood, papermaking and cotton industry also take part in the developmental process of these 
polymers structural forms biomaterials [2] that might be combined in biorefineries [3] to develop a wide variety of production like resources, electricity, chemicals and fuel.

The improvement in lignin by main evolution of biorefinery productions and new developments to change this large biomolecule into different other valuable raw material [4]. Analysis of lignin impacts several changes to it from its native state making it difficult to have an exact structure of lignin within the cell wall. However, there are isolation methods that can be used to get a better idea of the characteristics of a less severely modified lignin. One such method involves the resizing of wood into a fine flour through ball milling, using cellulose degrading enzymes to remove the bulk of the polysaccharides, and then an acidosis reaction to break several of the lignin carbohydrate linkages. The separation of this enzymatic mild acidosis lignin (EMAL) conserves numerous features related to lignin applied as a standard to associate with different lignin separation methods. Analysis by means of quantitative nuclear magnetic resonance (NMR) spectroscopy, this exposes the quantity of functional groups related to the amount of lignin.

Many lignin's comprises $4 \mathrm{mmol}$ aliphatic $-\mathrm{OH}$ groups associated to the side chain/gram of lignin and $0.2-1 \mathrm{mmol}$ free phenolic groups/gram of lignin. Also, it is possible to analyse lignin inside the cell wall lacking the requirement of isolation. Method involves the crushing of wood into a fine dust and then consuming solvents for cell wall dissolution. Dissolved wood is examined using two-dimensional (2D) $13 \mathrm{C}-1 \mathrm{H}$ heteronuclear single quantum coherence (HSQC) NMR spectroscopy. This procedure can regulate the comparative concentrations of interunit lignin structures that helps in understanding the lignin structure.

There are two ways that happen through delignification. First one involves rupture of key lignin-carbohydrate associations. This breakage of bond will permit extractability of lignin as observed through mild acidosis of lignin where dilute $\mathrm{HCl}$ is utilized to break these associations. The second one includes breakage of some of the interunit bonds of lignin which may cause the reduction of molecular weight. Hence, delignification technologies dramatically influence lignin functionality and molecular weight. Consequently, the properties related to lignin solubility are altered. Numerous researches have shown that lignin can be fractionated by using several solvents with highly dissimilar solvent parameters. Minute quantity of lignin can be soluble like in toluene (non-polar), non-hydrogen bonding solvents like dichloromethane $\left(\mathrm{CH}_{2} \mathrm{Cl}_{2}\right)$, whereas other may be soluble in extra polar solvents like aliphatic alcohols. The solubility difference of the fractions clarifies the heterogeneous nature of lignin even if it is from a softwood isolation that comprises $95 \%$ guaiacyl lignin. Delignification can alter the lignin by addition of the reactants such as Sulphur or alcohol to the lignin or enhances the molecular weight by reactions of lignin with itself through delignification. These separation processes result in lignin that comprise acidic groups, lose aliphatic $\mathrm{OH}$ groups, increase the free phenolic groups by breakage of the linkage, that comprises more $\mathrm{C}-\mathrm{C}$ bonds within units.

\section{History of Lignin}

About 170 years ago, the French chemist, Anselme Payen (1795-1871) dried woods with nitric acid $\left(\mathrm{HNO}_{3}\right)$ and sodium hydroxide, recovering two dissimilar products (Marton et al., 1966). 
The first one was denoted as "cellulose" by him and the other ingredients with high carbon concentration was slow as a coating material, in which the cellulose was implanted.

Discovery of lignin by Anselme Payen (1839) was initially defined as the encrusting material in wood. Scientists were confused by the nature of this widely present material [5]. Though lignin was observed to be rich in carbon concentration than carbohydrates, the chemistry remained unclear for a long time. Consequently, since the last century, the lignin structure was labeled as a complex polymer composed of asymmetrical branched units. Lignin is noticed in all vascular plants, commonly between the cells, within cells and cell walls. The polyphenolic lignin structure is well known for its role in woody material to give resistance to chemical and biological degradation. This is because of their hydrophobic nature and insolubility in aqueous systems stopping access of degrading chemicals and organisms [6].

Previously, the nature of the plentiful substantial was not known, and its chemical construction of its constituents persisted as unidentified for a period of time. The quality of lignin was explained by Bente, and as late as 1890, Benedikt and Bamberger observed that get together of cellulose, lignified important of lignin contains methoxyl groups. Lignin chemistry is in main slice because of the struggle of Peter Klason (1848-1937), who devoted high devotion to lignin and its properties containing its description, experimental bases show that but also with his awareness, he explains that lignin is prepared by coniferyl alcohol [7]. Several procedures discussed in a study were beneficial for research of lignin, and his procedure is highly in use [8]. Freudenberg also contributed to lignin study. He extracted lignin from wood by different method and described it by watchful diagnostic purpose. According to this study, he defined lignin as an amorphous, a type of structural order based upon similar blocks containing phenylpropane components. According to these results of oxidative dehydrogenation of lignin, he suggested that the chief linking systems would be $\mathrm{C}-\mathrm{C}$ and ether linkages, latter otherwise alkyl-aryl ether linkages [9]. At the end, the structure of lignin formula has several studies for its clarification. Thus, Adler projected in 1961 the first formulae including 12 phenylpropanoic units connected by $\mathrm{C}-\mathrm{C}$ and $\mathrm{C}-\mathrm{O}$ bonds, while Freudenberg was familiar with more complex structure for lignin built on 18 units in 1965. NMR studies exposed lignin structure polymer has next been published by Ludwigand Nimz for softwood and beech lignin, individually. During last few years, increase in care on lignin is visible by the extensive number of reviews, books, publications and patents, containing a wide diversity of subjects and fields of application [10]. These are likely to clarify the structural procedures and reactivity of lignin. Some of them are the financial types for their use to produce polymers. There are some original contributions of Glasser and Sarkanen who had greatly shared on the studies of lignin's structure and have published a lot of researches publications on lignin and the linked financial parts.

\section{Lignin functions}

Lignin is an important constituent of the structural framework in plants forming part of the primary elements of the cell wall. By viewing the point of evolution, lignin has been attributed 
as the terrestrial variation that allows significant vertical growth. As an important part of the cell, lignin provides support to plant by communicating rigidity to the cell wall. The plant resists ecological stresses because of building blocks of cell wall [11]. Lignin provides rigidity to the plants but in aggregation with the hetero-polysaccharides, it enhances flexibility which is central for suitable response to dynamic loads from wind and snow. Additionally, lignin changes the polysaccharide network to make it resistant to foreign organisms. Lignin helps in the protection of woody tissues from microbial and fungal attack covering the carbohydrate structure, causing reduced availability of enzymes for hydrolysis. Partial solubility and complexity of the lignin makes it tough for degradation by microorganisms [12]. Still, with the diversity of associations, harmful organisms for wood require the breakage of aryl carbon bonds and aryl ether bonds requiring increasing the cost of production of specific enzymes or developing non-specific pathways for delignification. Additionally, lignin is less hydrophilic in nature than the polysaccharides helping to alter the permeability of cell wall by sealing it and enabling water transport through the vascular tissue [13]. The aromaticity of lignin lends itself to improving the heat stability of wood. Lignin nature has been broken with separated technical lignin, changing it into carbon fiber by using controlled increased temperature. While lignin is more heat stable but the structure of lignin is greatly obstructed by the thermal change and scientists should be advised that lignin structure can alter by processing at higher temperatures used in the production some thermoplastic materials. This type of modification comprised of polymerization, loss of hydroxyl group and synthesis of new acidic groups.

\section{Sources of lignin}

The sources through which we obtain lignin biomass are the extraction and the secondary treatments those having high impacts on its mechanical and physical properties. Lignin is derived from numerous sources like pulp, wood and paper, sugarcane and cereal straws using variety of pulping methods. The lignin content in woody plants from angiosperms and gymnosperms is the maximum with the order of $30-40 \%$ whereas other sources only comprise about $3-25 \%$ in terms of weight [14]. The pulp and paper sector harvest a large quantity of lignin with greater potential by future lignocellulosic biorefineries. Negligible lignin is recovered from grass leaves and solid waste in urban and rural areas where their lignin content is assessed to be less than $15 \%$.

\subsection{Wood}

In the middle lamella, lignin comprises non-uniform thickness and in the primary and secondary cell walls depending on the plant species and the type of cell. Roughly $70 \%$ of the total lignin biomass of the cell wall is concentrated in the thick layer of secondary wall. Quantity and quality of lignin alter naturally among wood species with $19-28 \%$ in angiosperms and $24-33 \%$ in gymnosperms. Hardwood in angiosperms in general comprises more hemicellulose and low quantity of lignin than softwood in gymnosperms [15]. Not only the quantity of lignin varies between hardwoods and softwoods, their concentration also varies in the location within a tree. 
The immature wood has higher concentration of lignin than latewood. Lignin content is also flexible within different populations of plants in the same genus. The average concentration of lignin ranges $25 \%$ in Pinus monticola to $30 \%$ in Pinus palustris within the genus Pinus.

Lignin in angiosperms is syringyl-guaiacyl type and in gymnosperm is naturally guaiacyl with limited p-hydroxyphenyl lignin in both forms. Both structures are different arising from the linkages that can occur during polymerization. Guaiacyl lignin can experience coupling reactions at the five positions of the phenylpropane unit and this delivers a substantial place for cross-linking and branching reactions, that particularly occur during delignification process. The occurrence of syringyl units makes angiosperm (hardwood) lignin more readily detached during pulping process by limiting lignin forming condensed structures without the open methoxy position in the syrginyl units. In compression-wood lignin, it is difficult enough to hydrolyze as it comprises a higher amount of condensed p-hydroxyphenyl units [16].

\subsection{Pulp and paper industry}

Species containing hardwood and softwood, and some types of once a year plants, have marketable interest as a basis of cellulose fibers to produce board and paper products. Lignin is not easy to separate in a native form from plant material. The paper and pulp industry is primarily commercial way of lignin, the delignification process, though, modifies lignin to various grades. In technical fiber liberation processes, like sulfite or alkaline pulping, vast amounts of lignin are liquefied as alkali lignin and lignosulphonates, respectively. Large quantity of lignin was made available every year from the paper and pulp industry as byproducts of the delignification process. These sulfite or sulfate lignins have fluctuating levels of covalently bonded sulfur ensuing in the polymer with different characteristics that the original lignin [17]. Typically, impurities in lignin including low molecular weight sugars and resin acids are removed through distillation method. Kraft lignin is typically purified by Kraft black spirits, which are complex assortments of fibrous materials and dissolved organics such as hemicelluloses, lignins, acids, sugars, and resins and inorganic salts such as ash [18]. Modern technology in increasing lignin recovery from black liquor using carbon dioxide acidification that has been transported to industry and has manufactured a readily accessible dry lignin dust stream [19].

\subsection{Sugarcane bagasse}

Sugarcane bagasse is the leftover fiber after sugars have been removed. As an agro-industrial residue, Saccharum officinarum (sugarcane bagasse) is another source of lignin biomass. It is a byproduct of the sugarcane industry with almost 32-34\% cellulose, 19-24\% hemicellulose, $25-32 \%$ lignin, $6-12 \%$ extractives and $2-6 \%$ ashes $[20,21]$. Composition of sugarcane bagasse is close to the other plant cell walls. Each class of plants, grasses, gymnosperm and angiosperm manufacture higher lignin content in one type of the phenylpropane repentance. Sugarcane bagasse lignin comprises a higher quantity of H-type lignin, p-hydroxyphenyl, and result in lower methoxy content than softwood and hardwood lignins [22]. Approximately $250-280 \mathrm{~kg}$ of bagasse are produced from processing ton of sugarcane which roughly produced 54 million tons of bagasse every year [23]. Now, a large quantity of bagasse is burnt as a low-grade fuel for recovery of energy and a limited quantity is being used to make pulps, board materials and composites. 


\section{Agricultural residues}

The benefits to use agricultural residues are threefold for economic, environmental and technological results related to a green economy. Dissimilar from pulps of wood, pulps of agricultural can get by means of more ecologically benign pretreatment and bleaching methods [24]. In classical wood pulping methods, maximum bleaching of pulp takes place using chlorinebased chemicals or chlorine whereas straw is treated with slight additions of chlorine-free chemicals that results without the production of toxic chemicals. Additionally, agricultural residues comprise generally a more permeable structure and a lower lignin concentration than woody plants which enhances their pulping procedures. Agricultural residues may be rice and wheat straws which are discussed in this section. Rice straws also called as cereal-straw are additional source of lignin production. Total rice straw production of the word, Oryza sativa, is 525 million tons per year.

\section{Chemical structure of lignin}

The lignocellulosic material is a compound of biopolymers with cellulose intertwined (35-83\% dry weight), hemicellulose (0-30\%), lignin (1-43\%) and some extra complexes (xylose, arabinose, tannin, etc.) [25]. In woody plants, lignin plays a key role in a construction and strength to cell walls, changeable fluid movement by wary in contradiction of biochemical straining by struggling enzymatic breakdown of other complexes [26]. Its structure includes phenylpropane components, linked from three aromatic alcohol ancestors, p-coumaryl, coniferyl and sinapyl alcohols. The phenolic administrations that started from these monolignols are said phydroxyphenyl ( $H$, from coumaryl alcohol), guaiacyl ( $G$, from coniferyl alcohol) and syringyl (S, from sinapyl alcohol) moieties. Overall the biological lignification way, the monolignols<smiles>COc1cc(/C=C/C=O)cc(Oc2cc(C(O)C(CO)Oc3ccc(C(O)C(=O)CO)cc3OC)ccc2Oc2cc(C(O)C(=O)COc3ccc(C(O)C(=O)CO)cc3)ccc2O)c1</smiles>

Figure 1. Chemical structure of lignin. 
components are connected together by means of radical link reactions [27] to synthesize a complex 3D molecular structure that comprises a great variety of bonds with naturally around $50 \%$ ether linkages [9]. Lignin composition and content are predisposed by the environment andalso by the species. Hardwood lignins comprise principally of $\mathrm{G}$ and $\mathrm{S}$ units and traces of $\mathrm{H}$ units [26], however softwood lignins majorly comprise $\mathrm{G}$ units, with low levels of $\mathrm{H}$ units. Grasses lignins-monocots-incorporate $\mathrm{G}$ and $\mathrm{S}$ units at analogous levels and more $\mathrm{H}$ units than dicots. Grounded on complete lignin structure projected by Adler in 1977, lignin is documented as a majorly branched polymer with a diversity of functional groups: aliphatic and phenolic hydroxyls, carboxylic, carbonyl and methoxyl groups. The chemical structure of lignin is drawn in the given Figure 1. The profusion of the chemical sites suggest different potentials for chemical changings and recommends that lignin might play a vital character as a new chemical predominantly in the development of supramolecular structure and aromatic chemicals [26].

\section{Extraction process and their resulting technical lignin}

Physical, chemical and biochemical treatments are used for the extraction of lignin from other cellulosic materials. The botanical sources as well as the pulping source which is also called as the delignification process have great effect on the final structure, purity and corresponding properties of the lignin [28]. Cleavage of ester and ester linkages is the basis of the pulping process and the resulted technical lignin are different from the plant lignin. In this part, our main focus is to recover the lignins by the different extraction processes which are commercially available. Sulfur and sulfur-free processes are the two main categories which are shown in Figure 2. Differences in chemical structures effects the lignin reactivity like for the various modification [24].

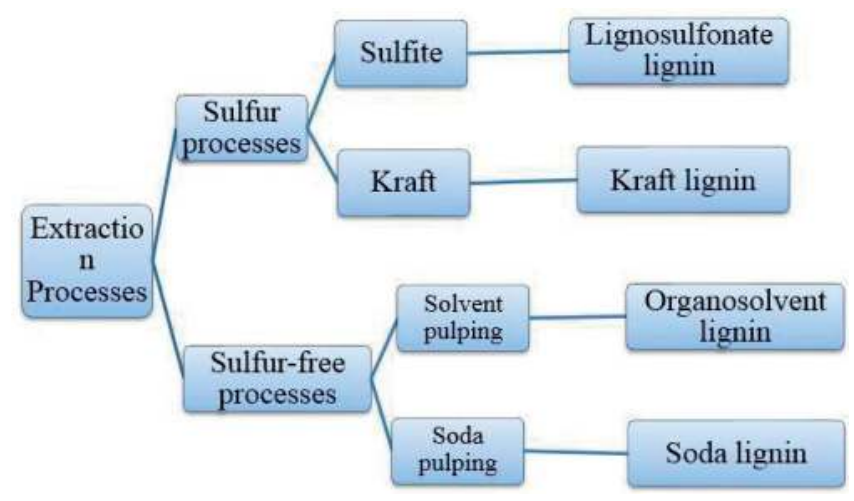

The meal of wood weighted $25 \mathrm{~g}$ after extraction was kept in a percentage liter beaker, three bottles tight with the reflux condenser, through dipping funnel and a nitrogen jar. In the water bath flask heated for 10-15 min, oil was attached to pump that attached and the solvent having 


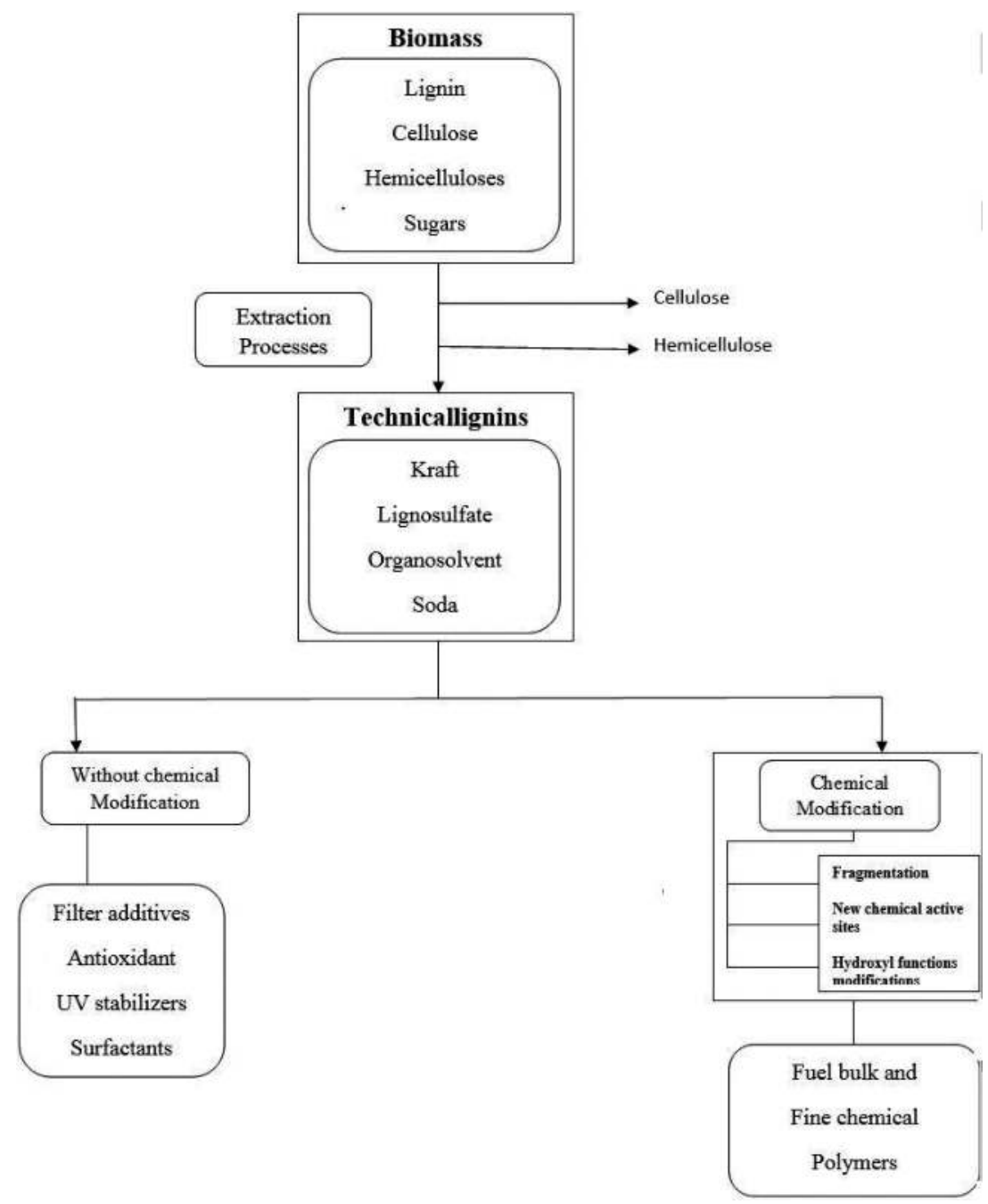

Figure 2. Isolation of lignin process.

$46 \mathrm{~g} \mathrm{HCl}$ as dry gas is poured by the dropping funnel. Heat the reaction mixture and gently refluxed for changing ages of time of $1-8$ and $48 \mathrm{~h}$ beneath the nitrogen air [29]. For the analysis of sample, the use of aspen wood reaction mixture was homogenized utilizing a stirrer. Reaction mixture cooled, filtered while nitrogen enclosed and the washed accumulation by using filter by an extra process comprising similar dissolvable. Remaining pulp was dehydrated until the constant weight come and examined for methoxyl concentration. Then filter the solution and filtrate was killed with excess of $\mathrm{Na}_{2} \mathrm{CO}_{3}$ and allowed to remain overnight. We supposed to reduce the weight of liquid layer by using nitrogen spill [30]. 


\section{Lignin isolation from the spruce wood}

In preceding trials to reason about the fairness of dissimilar dissolvable constituents, originally separated spruce wood prospered in the dissolvable medium having $0.2 \mathrm{~N}$ (solution by weight), $\mathrm{HCl}$ dry gas and nitrogen air refluxed for $4 \mathrm{~h}$ time duration.

The solvents selected were dioxane-methanol and chloroform-methanol as suggested by dioxane-water, Schuerch and dioxane. Than filter the reaction mixture, and the filtrate, after equilibrium with $\mathrm{Na}_{2} \mathrm{CO}_{3}$, was concentrated to a little capacity. The lignin was encouraged by compelling this focus, as a fine stream, under the superficial of $1 \%$ sodium sulfate solution. The lignin was expelled by the process of centrifugation and decantation also the mother mixers were thoroughly removed with ether [31]. The leftover wood supper, the lignin, and the ethersolvent concentrate were dried to steady weight and examined for methoxyl content. The procedure of isolation of lignin from spruce wood is given in Figure 2. It was examined that the alkylation reaction and disclosed as being because of the etherification of benzyl liquor gatherings or the re-etherification of benzyl ether gatherings [32].

There is an impressive lessening in the aggregate accessible lignin items when contrasted with those obtained either by the one-stage $2.5 \mathrm{~h}$ or the one-stage $4.0 \mathrm{~h}$ extraction. The synthetic idea of these items detached by the progressive stepwise technique changed significantly, demonstrating the lignin substance [30]. It must be called attention to that every wood deposit was dried first noticeable all and phosphorus pentoxide in vacuum desiccator, and it is possible

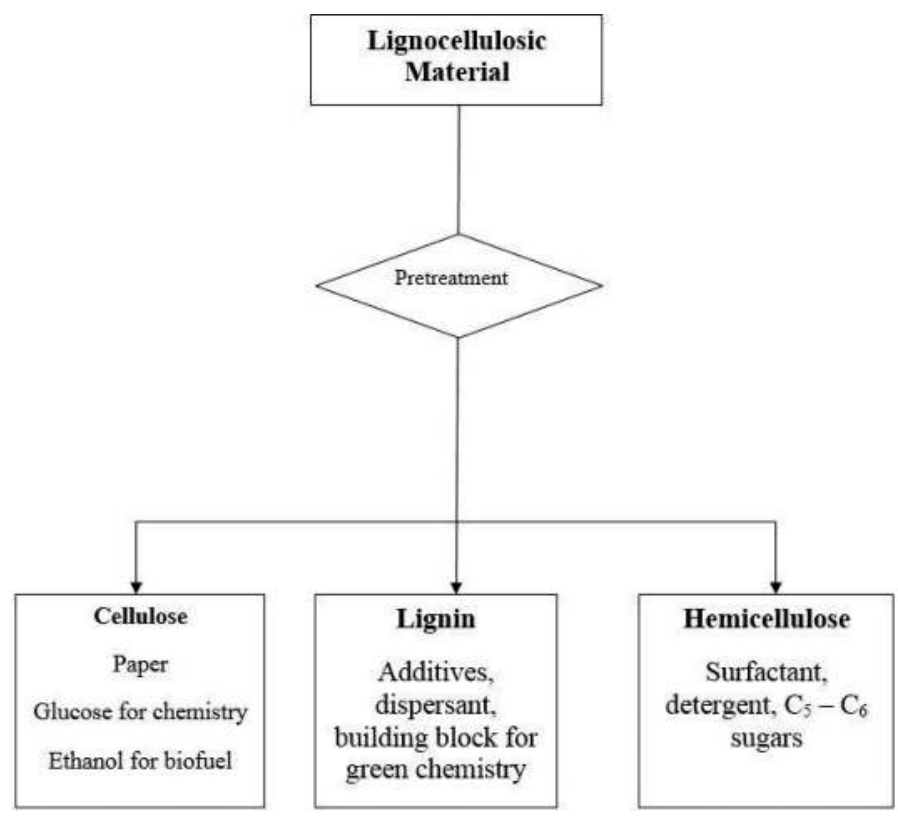

Figure 3. Digestion of lignocellulosic material. 
that amid this time condensation or oxidation happens that diminishes the simplicity of ensuing isolation. The subsequent reaction items were considered some time recently, the lignin recouped by precipitation into $1 \%$ sodium sulfate, and the ether-dissolvable oils removed from the fluid filtrate [33].

The benefit of utilizing fluid dioxane over dioxane alone is demonstrated by the fundamentally expanded yield and n-methoxy substance of the disengaged lignin as shown in Figure 3. Doubtlessly, in the watery framework, some sugar or other non-methoxyl-containing parts that show up with the lignin in the unadulterated dioxane extraction has been isolated and show up rather in the ether remove offering ascend to the moderately bring down methoxyl substance of this portion.

\section{Lignin as antioxidant}

Utilization of the biomass product which is obtained at the technological cycle is the concept of biorefinery. In the chemical and biochemical processes lignin is separated as the byproduct from the lignocelluloses. It is an important component of the polymer system due to the good potential of recognition. About $98 \%$ of the total lignin is burned to improve the energy balance in the main process while only minute quantity of lignin (1-2\%) is used to make the valueadded products [34]. Lignin acts as binder, plasticizers, sorbent, composite of materials, additive for food preparation and polymeric carrier of biologically active agents. These are the traditional applications of lignin [35]. Lignin also acts as the antioxidants. Lignin acts as the stabilizers in that reaction which are induced by oxygen and its reactive species and also have the property to slow down the aging of biological systems and composites. The antioxidant property of lignin shows lots of applications in industry, healthcare and agriculture [36]. Due to high thermal and biological activity, lignin is used in place of those molecules which have lower molecular weight and also where the antioxidant activity of the single molecule is insufficient. For the composition and structure of lignin, polydispersity and chemical heterogeneity along with MMD is asked so that its application as the antioxidant can be determined. The efficiency of lignin as antioxidant is related to its structure and solubility [37]. It is difficult to allocate the lignin as antioxidant efficacy to specific organizational elements due to the complex structure of the lignin with comparison to synthetic antioxidants or polyphenols which are naturally defined like flavonoids and tannins [38]. For the antioxidant activity of the lignin, free phenolic hydroxyl groups and ortho-methoxy substitution in aromatic rings are essential. But some compounds like the carbonyl group in the side chain shows the negative effect on the antioxidant activity of the lignin. Radical scavenging activity of lignin is decreased due to various factors which are important in functioning of lignin-like high molecular weight, polydispersity and heterogeneity [39]. In situ, lignins are embedded in the complex network system which contains the different types of polymers including protein, macromolecules or molecules according to the biological region, isolated lignins and contained mixtures also have the ability to change the antioxidant activity of the lignins by changing the polarity like in the presence of polysaccharides which are more polar than the lignin and by decreasing the phenolic compounds concentration. Nowadays our aim is to investigate the novel type of 
technical lignin. BIOLIGNINTM, a product of biomass refinery technology which is recently developed (CIMV, France) [40] realizes the plant biomass fractionation and also three other compounds were obtained, celluloses, hemicelluloses and lignin, and the lignin itself is a commodity chemical and a raw material which is used for further processing. Fractionation of the technical lignins with the organic solvent which is a best way for obtaining the molecular mass distribution (MMD), component composition and for the production of value-added products [41]. Present work was done for the evaluation of the suitability of fractionation of BIOLIGNINTM, which acts as a tool form obtain the products which have a good antioxidant property specifically for polyurethanes (PU) which is a composite material on the basis of polyether's-polyols and aromatic isocyanates, for example, elastomers. So that is why BIOLIGNINTM was fractionated by using the two organic solvents which are of different polarity through sequential extraction [42]. Each fraction was characterized by the structure of lignin macromolecule and due to presence of the carbohydrates and other mixtures. These characteristics were then compared with the data of effect on lignin addition on model of thermos-oxidation destruction. Antioxidant efficiency of lignin fractions were indicated by PU elastomers [43].

\section{Lignin potential}

Only $2 \%$ of lignin is used for the combustion and energy production while around 50-millionton lignin is produced every year by paper and the pulp sector [44]. Lignin structure, heterogeneity and the industrial processing costs for delignification are the main reasons for the limited utilization of the lignin $[45,46]$. For the removal of these limitations, modification of several types is used which increases its chemical reactivity, decreases the brittleness of the lignin resultant polymers, regularity, increases its solubility in the organic diluents and progress the comfort of processing the lignin [47]. Lignin potential is considered important for the production of the additives, coating material and resins [48]. Synthetic polymers and the aromatic chemicals can be replaced with the new renewable aromatic compounds [49]. It is experimentally proved the high antioxidant capacity of the lignin and its applications in the polymer enhancement [50]. Lignin depolymerization can be used on large scale for the production of valuable chemicals due to the lignin macromolecule structure of the lignin with the many phenolic compounds [51]. Lignin is also used in the fabrication of composite material. Finally, it was showed that exterior grade particleboards which are made by the lignin-based adhesives can successfully met the requirements of international standards.

\section{Application of lignin}

The handiness of commercial lignosulfonates items come from their scattering, authoritative, complicated and emulsifying characteristics. Industry initially started to utilize lignins in the 1880s when lignosulfonates were utilized as a part of calfskin tanning and color showers. From that point forward, lignosulfonates have even discovered applications in nourishment items, filling in as emulsifying factory machine a creature encourage and as crude material in 
generation of vanillin [52]. Enthusiasm for the physiological part of bioactive mixes show in plants has expanded drastically finished the most recent decade and it is quite compelling in connection to human wellbeing. Notwithstanding customary application systems, cancer prevention agent is a huge use of lignin. Lignin is called a free radical borrower, and relaxes the reactions started by oxygen and type of free radicals [39]. Past researches in our study center have shown the cell support action of lignins got from sugar stick [53]. To arrange of negative impacts, it is significant to do soundings of possible eye and skin bothering. These categories of studies are compulsory for all type of chemicals [54], and are done with a change of the past test.

\section{Antimicrobial properties of purified lignin}

Antimicrobial possessions of the lignin are well known. Procedure of hard wood development is linked to potential harmfulness to microorganisms of phenolics deposited; this is due to natural durability of the wood species. Phenolic compounds are used in the food preservation process due to the presence of phenolic compounds in lignin which have the ability to inhibit the microbial growth with phenolic acids and flavonoids. Carvacrol and cinnamaldehyde, which are the phenolic monomers, are used in meat, rice, cheese and in fresh fruits and vegetables [54]. However, some applications are not of scientific consideration like the lignin has the potential to improve the intestinal health and animal welfare.

Dietary Alcell lignin reduced concentrations of Escherichia coli, when compared to antibioticfree diet or containing one antibiotic, was suggested in the further research [55]. Main cause of food borne illness is basically the contamination of the intestinal Escherichia coli with the poultry carcases in the slaughter houses, and at the same time antibiotic resistant gene is spread in food chain though the poultry litter [56]. Litter Escherichia coli is also the pathogen of the cellulitis, which is the cause of the carcass condemnation at processing plants [57]. According to the new finding, the load of Escherichia coli can be reduced in the chicken intestine and in litter by the purified Alcell lignin and in this way, we can improve the safety of poultry products and also the cellulitis. Mechanism of lignin action is not well-defined. Polyphenolic compounds of lignin cause the cell membrane to damage and also cause the lysis of bacteria which also causes the release of cell contents. Carvacrol, thymol and cinnamaldehyde, a phenolic monomer, which also possess the antibacterial activity [58, 59]. Antimicrobial activity of the carvacrol and thymol is because it causes the integration of the cell membrane and cell content also releases. While cinnamaldehyde has the ability to penetrate in the cell membrane of bacteria which causes the reduction in the intracellular $\mathrm{pH}$ and causes the ATP depletion [60]. The antibacterial mechanistic actions are seen in many phenolic compounds.

\section{Application of lignin in ethanol production}

In the production process of biomass, ethanol lignin exists as in two forms; insoluble in residues and soluble in pretreatment solvent. The lignin which is soluble in solvent is restored by the process of washing and purification which removes the excess water and the extraction 
process is used for the insoluble lignin [61]. By the comparison of the lignin residues with the burning lignin for heat and power, high-value co-products of biomass ethanol are expected. It is a challenge to use the lignin residue at economical level for commercial process, but it is necessary for economic viability of such plants and it is beneficial to environment and also of high profit. Lignosulfonates is a commercial lignin, which is produced as a byproduct in paper and pulp industry. Lignosulfonates also acts as the emulsifiers in the animal field and in the production of vanillin used as a raw material. Lignin possesses antioxidant and antimicrobial properties as a complex phenolic polymer [39]. Different numbers of factors influence the chemical structure of the lignin which can be modulated be different means including botanical regions, condition of extraction from in situ network and the environmental conditions of growth. Delignification techniques consist of two processes: firstly, cleavage of the covalent lignin and then the solubilization of polymer fragments. Different techniques are used for the delignification of the lignin use of organic solutions, use of acid or alkali or several other parameters (time, temperature, etc.). These conditions affect the chemical structure of the lignin (molar mass, cross-linking, density and the functionality) and it's bioactive. Biomass ethanol as biofuel has many advantages including economic, environmental and social stability [62]. Corn stover is largely available that is why it is considered a good candidate for the production of ethanol. Ref. [63] defined that $0.25 \mathrm{~kg}$ ethanol can be made from $1 \mathrm{~kg}$ (dry basis) of corn stover, and it has been predictable that $0.34 \mathrm{~kg}$ ethanol can be formed from $1 \mathrm{~kg}$ (dry basis) of corn stover in the close future [64]. For the production of 150 million $\mathrm{kg}$ of ethanol, we have to consume 450 million $\mathrm{kg}$ of corn stover per year. It contains almost $18 \%$ lignin so per year almost 81 million $\mathrm{kg}$ of lignin will be generated [61].

\section{Antioxidant activity in RBCs of human}

Antioxidant capacity in red blood cells is evaluated by the inhibition of the human erythrocytes hemolysis which is induced by the AAPH (2,2-azobis (2-amidinopropane)) (a peroxyl radical initiator). With the help of vein puncture, blood samples were taken from different healthy individuals. Blood was centrifuged at 10,000 rpm for $10 \mathrm{~min}$ and washed with the help of phosphate buffer saline (PBF). After washing supernatant coat was removed carefully and then these washed red blood cells are suspended in the buffered saline. Hemolysis of erythrocytes was determined by the AAPH adjustment. Ref. [65] of a method defined by [66]. For the induction of hemolysis, $25 \mu \mathrm{l}$ of aliquots of RBCs suspension were preserved at specific temperature in the presence of $100 \mathrm{mM} \mathrm{AAPH}$. $\mathrm{IC}_{50}$ of the hemolysis is determined which was induced by the AAPH. By using the spectrophotometer at $540 \mathrm{~nm}$, hemolysis was monitored. Inhibition of hemolysis which was obtained by AAPH is studied at the different concentrations of lignin. For all the lignin studies, inhibitory effect is concentration dependent, the higher the concentration, greater will be the inhibitory effect. Most of the antioxidant lignin, bagasse, has a $100 \%$ inhibition effect at the low concentration. For the $\mathrm{IC}_{50}$ values of the lignin, dose response curves are calculated [52].

It is dangerous to give these biological actions to specific structural components due the molecular difficulty of the lignin as related to the actions of chemically well-defined flavonoids and tannins [37]. Lignin can resist the viability and growth of effected cancer cells because it is 
a major component of dietary fiber and in this way, lignin can inhibit the enzymes which are related to the synthesis of superoxide anion radicals [67]. In a new study, it is examined that the lignins which are ready at high temperature, increased catalyst, longer reaction period and dilute ethanol displayed high antioxidant action [68]. It is compulsory to study the result of new properties on skin and eyes. We studied the lignins for skin and eye irritation. It is shown that all the lignins are non-irritants to skin and eyes after application of 0.2 and $0.5 \mathrm{~g}$, respectively. None of the compounds showed irritation from mild to severe (i.e., severe erythema, oedema). So, these lignins are studied as non-irritants to skin and eye, however, more studies should be performed for using them in topical formulations [52].

\section{Cell reinforcement movement}

The examination of potential latest applications of lignin in many imaginations is of strange significance. Among these applications the use in the restorative ground would be of intrigue mainly because of their cancer stoppage agent capacity. The inhibitory result is fixation in need of for every one of the lignins studied, being the best inhibitory effect at the most astounding focus measured. Bagasse, the most cell support lignin, talented a 100\% inhibitory effect at least fixations (from $100 \mathrm{~g} / \mathrm{ml}$ ). Amount reaction curves were determined for the lignins strained over a scope of focuses, allowing IC50 esteems to be acquired (fixation starting half limit on hemolysis started by AAPH) [68]. These qualities uncovered Bagasse as the lignin with most astounding cancer prevention agent action, on account of its low IC50 esteem and with a comparative incentive than those introduced by epicatechin. Heterogeneity as far as segment creation (starch admixtures) and polydispersity is the factor, which can diminish definitely the cancer prevention agent proficiency of segregated lignins [39]. Because of the sub-atomic multifaceted nature of lignin, it has been hard to allot these organic exercises to particular basic segments, contrasted with the exercises of synthetically characterized tannins and flavonoids [37]. As a noteworthy segment in dietary fiber, lignin can hinder the movement of compounds identified with the era of superoxide anion radicals and block the development and practicality of disease cells [67]. In a current paper, it has been shown that, as a rule, the lignins arranged at lifted temperature, longer reaction time, expanded impetus, and weakened ethanol demonstrated high cancer prevention agent action [68]. Additionally, considers are important to be led to comprehend the connection between substance structures of the lignins announced in this paper and their cancer prevention agent exercises [52].

\section{Hydrogels application based on lignin}

As observed in the previous section, the biorenewable polymer lignin can be applied for the hydrogel applications as a starting material. The development of hydrogels on the most current years has seen a rapid move from industrial to consistent polymers as one of the energetic segment [69]. The main attention for polymer classification based on hydrogels residue to their innate properties, like, biodegradability, biocompatibility, little poisonous value, eco-agreeableness and defenselessness to enzymatic lying. Biopolymer applications 
based hydrogels are in biomedical, water sanitization, mending frameworks, biomimetic platforms and medication transportation devices [54]. Between massive typical polymers, lignin is an interesting member in hydrogels due to its focal links as communicated before that makes it an elastic physical for common applications in numerous fields. There is an extraordinary set of quantity of researches obtainable on the consumption of lignin, for example, spin in hydrogel polymer applications. So, additionally, we must do undercover persona lignin kinds founded upon hydrogels together within potential applications in feature. Basic lignin or Kraft produces green polymer hydrogel [30]. The both procedures of lignin used as a part of this examination were limited from crushing alcohol and described UV/FTIR spectroscopy.

The hydrogels education was fused by the use of unite copolymerization technique. The idea of acrylamide and poly vinyl liquor wrapped to promote allowance of acrylamide monomer is done by join copolymerization reaction. These hydrogels were showed applying FTIR and UV spectroscopy. These hydrogels were then visible to water absorptive and deswelling education. It was detected by training that the basic lignin hydrogel had in height inflammation quantities, reduced aquatic take-up and inflammation charges when related with the hydrogel Kraft lignin 1 . The condensed deswelling performance was qualified to the ideal system construction of the basic lignin, while the height inflammation amount was qualified to the cooperative support within the wipe subdivisions and the mass grid. Mutually, types of hydrogels were secondhand to think about the impression of table salt $(\mathrm{NaCl})$ on the interest size at normal temperature and distension at several grades. It was detected that the delay of sodium chloride brought about an insistent digestion size of the hydrogels and this action came because of the reduction in the weight alteration within the gel and the outer explanation [33]. Lignin created hydrogels were similarly decided using alcohol as the back matrix by a similar study. Dark alcohol is a combination of sugars and is one of the major automatic wastes that outcome from the mashing strategy [70]. The black alcohol in this research was learned from basic crushing of rice stubble.

The hydrogels were set up by artificial cross-connecting process. In this process, dual discrete cross-connecting methods, exactly, cross-connecting by expansion reaction and cross-connecting by fundamental polymerization were applied. In cross-linking by radical polymerization, ceric ammonium sulfate was used as creator within the vision of N,N-methylenebisacrylamide to do bond copolymerization of poly vinyl liquor (PVA) and polyacrylamide (PAAm). Anyhow, amid the cross-connecting by the progress reactions, the polymerization of hydrogels was confirmed without the originator. The hydrogels organized using the individual systems were labeled by FT-IR spectroscopy and examining electron microscopy (SEM). The hydrogels settled applying radical polymerization were happening to show an increased inflammation size, $60 \%$, associated with $27.27 \%$ developed from the hydrogels that were set up by development response. $\mathrm{NaCl}$ effect on the digestion ability of these hydrogels was also educated at countless temperatures and $\mathrm{pH}$. From investigation, it was hypothetical that lignin including dark alcohol can be used as green hydrogel experiences [5]. Heat touchy lignin constructed hydrogels had likewise been set by using the acidic destructive lignin. In this study hydrogels link copolymerization reply was used to set the hydrogels. The copolymerization response was done using acidic lignin and N-isopropyl acrylamide (NIPAAm) within the sight of N,N-methylenebisacrylamide 
(MBBAm) as the cross-linker and $\mathrm{H}_{2} \mathrm{O}_{2}$ as the originator. The common hydrogels were later predictable for their warm, morphological and inflammation performs. The opening calculation in the hydrogels was noticed to rise by the development in the acidic lignin and was complete from the SEM slow. The thermogravimetric study of these hydrogels is showing their break down in the heat range of $400-410^{\circ} \mathrm{C}$, although the difference review calorimetry (DSC) consider established to minor the basic explanation temperature (LCST) of $31^{\circ} \mathrm{C}$. The point-by-point inspection of these hydrogels stated their temperature touchy countryside. Lignin founded hydrogels were equally approved aimed at their important usage as aerogel and cryogels [69].

In the field of material applications, the cell reinforcement action has been researched in the point of utilizing lignin as a characteristic substitute of engineered cancer prevention agents required for the detailing of polyolefins [71]. The similarity among lignin and polymer network could be effectively anticipated utilizing the dissolvability parameters figured after the Small, Van Krevelen and Hoy technique. A similar component ensuring polyolefins against radical oxidative debasement is significant for assurance of unsaturated fats. The utilization of regular cancer prevention agents to ensure lipids and sustenance has effective long history [72]. The capacity of lignin has prevented lipid peroxidation in human red platelets. Polymer bundling materials are collaborating with stuffed merchandise because of mass exchange between the two accomplices, which is impacting sustenance quality [73]. It is intriguing to make positive utilization of such a connection to guarantee a maintained conveyance of a dynamic substance, for example, the cancer prevention agent into the nourishment stuff. In that point, dynamic bundling is currently progressively utilized as a supply for dynamic substance conveyance [74]. Supplementing different procedures, for example, altered environment bundling, eatable covering or oxygen scroungers [75].

The goal of study is to research the potential of lignin to be utilized as a characteristic cancer prevention agent added substance in a dynamic sustenance bundling. The bundling framework picked was poly(lactide) (PLA) in light of its inexhaustible character. The incorporation of regular cancer prevention agents in PLA in the point of building up a dynamic material has just been proposed in writing [76]. Besides, a few investigations as of now exist indicating the practicality of consideration of lignin into PLA [77]. Two commercial salt lignins were picked due to their normal radical rummaging movement and their distinction in the free phenolic monomers content. PLA was mixed with lignin by twin screw expulsion and film tests were created by thermo-pressure. The impact of lignin amount and handling on the radical searching action was surveyed in an ethanol/water solution being a stimulant of greasy nourishments suggested by the European control for sustenance contact materials [78].

Assurance of lignin cancer preventive action is contradiction of DPPH free radical. Lignin cell reinforcement size remained examined by assessing free fundamental rummage impact. The DPPH radical probing exercises of organo-solvent lignin extraction and regular Kraft lignin were separated by minor modification technique as described by [79]. Quickly, a lignin test solution in $0.1 \mathrm{ml}$ of dioxane-water $(9 / 1, \mathrm{v} / \mathrm{v})$ was added to $3.9 \mathrm{ml}$ of a DPPH solution $(25 \mathrm{mg} / \mathrm{l}$ in ethanol) as the free radical foundation and kept for $30 \mathrm{~min}$ at room temperature. The decline of the solution absorbance, because of proton donating action, was restrained at $517 \mathrm{~nm}$ (UV2550, Shimadzu, Japan). The DPPH radical searching action was computed. Lignin cancer 
prevention agent capacity was contemplated by assessing free radical searching impact (DPPH). The outcomes showed the lignin acquired by acidic acid-water technique had the most astounding cell reinforcement movement [52]. Indeed, inquire about demonstrates the lignin has no unsafe impact on eyes and skin. In this manner, the high cell reinforcement capacity of lignin from the acidic acid-water strategy opens another application in corrective and topical plans.

\section{Cytotoxicity of lignins}

Possible applications of lignins in the corrective and pharmaceutical businesses expect them to be innocuousness. Potential skin bothering by a fixing or item is one of the different investigations embraced in the general evaluation process. Cell cytotoxicity measures are among the most well known in vitro bioassay techniques to anticipate the danger of an extensive variety of substances [80]. At present, couple of information exists on conceivable cytotoxic impacts of lignins. Thus, it is valuable to dispose of any undesirable impact. Moreover, it adds to describing their natural profiles. The cytotoxic impacts of the lignins were researched utilizing the cell layer uprightness of human keratinocyte $\mathrm{HaCaT}$ and murine fibroblast $3 \mathrm{~T} 3$ cells keeping in mind the end goal to foresee their skin disturbance potential. A colorimetric examine that measures the capacity of live cells to take-up unbiased red color was utilized. The 3 T3 nonpartisan red take-up examine was chosen since this test is prescribed by the US National Institute of Environmental Health Science (NIEHS) Interagency Coordinating Committee on the Validation of Alternative Methods (ICCVAM). The IC50 estimations of the lignins contemplated uncover that these mixes have cytotoxic impacts, however just at high focuses. Cytotoxic action increments with expanding presentation period with a focus subordinate reduction in the rate of impartial red take-up. The distinctions were not huge in all cases. The most cytotoxic compound was Curran 100 on HaCaT cells (no critical contrasts were found after 24, 48 and $72 \mathrm{~h}$ ) and bagasse in the $3 \mathrm{~T} 3$ cell line [36]. The minimum cytotoxic lignin in both cell lines was lignosulphonate. Lignins appear to be more cytotoxic in the keratinocyte cell line, particularly after $24 \mathrm{~h}$ (there are critical contrasts between the items).

A decent relationship exists between the cytotoxic impacts on HaCaT cells and on $3 \mathrm{~T} 3$, particularly after 48 and $72 \mathrm{~h}(\mathrm{r}=0.903$ and $\mathrm{r}=0.963$, separately; information not appeared). Contrasts between these two cell lines can, for this situation, be ascribed to contrasts in cell line affectability to the mixes considered. The cytotoxic information for the lignins were contrasted and that for epicatechin. The lignins are by and large similarly or less cytotoxic than epicatechin after 48 and $72 \mathrm{~h}$ of introduction, despite the fact that the $3 \mathrm{~T} 3$ cell line demonstrated a more harmful impact after $24 \mathrm{~h}$ presentation, on both HaCaT and $3 \mathrm{~T} 3$ cells (critical contrasts exhibited). The connection between potential cytotoxic properties and the cancer prevention agent capacity of lignins were likewise assessed. The most grounded cell reinforcement items were all in all likewise the most cytotoxic. In any case, the viable cancer prevention agent focuses are littler than the cytotoxic ones (cell reinforcement fixations are from 5- to 10-overlay lower) so the mixes are cell reinforcements at non-cytotoxic fixations. These informations are important to future applications, since they demonstrate that these lignins can be utilized over a powerful fixation run that is alright for the ordinary cell lines examined. A decent relationship was found among $\mathrm{Mn}$ and 
cytotoxic movement, particularly in the $3 \mathrm{~T} 3$ cell line. There was a reasonable pattern toward the heaviest lignin being the slightest cytotoxic [36].

\section{Conclusion}

It is examined that lignin extracts from remainder of biomass biofuel making displayed strong antioxidant properties and had little antimicrobial application. Commonly, the antimicrobial properties of lignin extracts were reliable with their antioxidant properties. Lignins and ligninderivated complexes are not now used in the para-pharmaceutical or cosmetic productions. It has been advised that the antibacterial result of Kraft lignin is related with the huge antiradical property of its methanolic portion. Nevertheless, normal application arrangements, cancer inhibition negotiator is a massive use of lignin. Neither of the lignins exhibited any injurious conclusion on eyes and skin. The high antioxidant capacity of the lignins considered together with their protection when useful on eyes and skin, open new outlooks in topical formulations and their potential use in cosmetic. The huge heterogeneity of lignins describes that it as very significant to complete the comprehensive characterization of the structures and properties of the lignins examined. It will be possible to regulate their behavior in different applications, and the behaviors in which their structures stimulate their biological properties.

\section{Author details}

Zahed Mahmood $^{1 *}$, Muhammad Yameen ${ }^{1}$, Muhammad Jahangeer ${ }^{1}$, Muhammad Riaz $^{2}$, Abdul Ghaffar ${ }^{1}$ and Irum Javid ${ }^{3}$

*Address all correspondence to: drzahiduaf2003@gmail.com

1 Department of Biochemistry, Government College University Faisalabad, Faisalabad, Punjab, Pakistan

2 Department of Allied Health Sciences, Sargodha Medical College, University of Sargodha, Sargodha, Punjab, Pakistan

3 Department of Biochemistry, Government College women University Faisalabad, Faisalabad, Punjab, Pakistan

\section{References}

[1] Haygreen JG, Bowyer JL. Forest products and wood science: An introduction. Forestry. 1998;71(1):79-80

[2] Gandini A. Polymers from renewable resources: A challenge for the future of macromolecular materials. Macromolecules. 2008;41(24):9491-9504

[3] Taylor G. Biofuels and the biorefinery concept. Energy Policy. 2008;36(12):4406-4409 
[4] Pickett J, Anderson D, Bowles D, Bridgwater T, Jarvis P, Mortimer N, Poliakoff M, Woods J. Sustainable Biofuels: Prospects and Challenges. London, UK: The Royal Society; 2008

[5] Sarkanen KV, Ludwig CH. Liguins. Occurrence, Formation, Structure, and Reactions. New York: Wiley-Interscience; 1971

[6] Banoub J, Delmas GH, Joly N, Mackenzie G, Cachet N, Benjelloun-Mlayah B, Delmas M. A critique on the structural analysis of lignins and application of novel tandem mass spectrometric strategies to determine lignin sequencing. Journal of Mass Spectrometry. 2015;50(1):5-48

[7] Rodríguez JJ, Cordero T, Rodríguez-Mirasol J. Carbon Materials from Lignin and Their Applications. In Production of Biofuels and Chemicals from Lignin. Singapore: Springer; 2016. pp. 217-262

[8] Brunow G. Methods to reveal the structure of lignin. Biopolymers Online. 2005

[9] Chakar FS, Ragauskas AJ. Review of current and future softwood kraft lignin process chemistry. Industrial Crops and Products. 2004;20(2):131-141

[10] Hatakeyama H, Hatakeyama T. Lignin structure, properties, and applications. In: Biopolymers. Berlin, Heidelberg: Springer; 2009. pp. 1-63

[11] Lopes FJ, Silvério FO, Baffa DC, Loureiro ME, Barbosa MH. Determination of sugarcane bagasse lignin S/G/H ratio by pyrolysis GC/MS. Journal of Wood Chemistry and Technology. 2011;31(4):309-323

[12] Verma SR, Dwivedi UN. Lignin genetic engineering for improvement of wood quality: Applications in paper and textile industries, fodder and bioenergy production. South African Journal of Botany. 2014;91:107-125

[13] Ten E, Vermerris W. Functionalized polymers from lignocellulosic biomass: State of the art. Polymers. 2013;5(2):600-642

[14] Smolarski N. High-value Opportunities for Lignin: Unlocking its Potential. Paris: Frost \& Sullivan; 2012. p. 15

[15] Bjornsson S. Advanced Control Methodology for Biomass Combustion (Doctoral dissertation)

[16] Novaes E, Kirst M, Chiang V, Winter-Sederoff H, Sederoff R. Lignin and biomass: A negative correlation for wood formation and lignin content in trees. Plant Physiology. 2010;154(2):555-561

[17] Sainsbury PD. Biocatalytic valorisation of lignin via genetic or chemical intervention of bacterial aromatic degradation pathways [doctoral dissertation]. University of Warwick

[18] Wallberg O, Jönsson AS, Wimmerstedt R. Fractionation and concentration of kraft black liquor lignin with ultrafiltration. Desalination. 2003;154(2):187-199

[19] Kouisni LA, Holt-Hindle P, Maki K, Paleologou MI. The lignoforce system: A new process for the production of high-quality lignin from black liquor. Journal of Science \& Technology for Forest Products and Processes. 2012;2(4):6-10 
[20] Sakdaronnarong C, Jonglertjunya W. Rice straw and sugarcane bagasse degradation mimicking lignocellulose decay in nature: An alternative approach to biorefinery. ScienceAsia. 2012;38(4):364-372

[21] Rezende CA, Ribeiro deAzevedo E, Polikarpov I, de Lima MA, Maziero P, Garcia W. Chemical and morphological characterization of sugarcane bagasse submitted to a delignification process for enhanced enzymatic digestibility. Biotechnology for Biofuels. 2011;4(1):54

[22] Doherty W, Halley P, Edye L, Rogers D, Cardona F, Park Y, Woo T. Studies on polymers and composites from lignin and fiber derived from sugar cane. Polymers for Advanced Technologies. 2007;18(8):673-678

[23] Canilha L, Chandel AK, Suzane dos Santos Milessi T, Antunes FA, Luiz da Costa Freitas W, das Graças Almeida Felipe M, da Silva SS. Bioconversion of sugarcane biomass into ethanol: An overview about composition, pretreatment methods, detoxification of hydrolysates, enzymatic saccharification, and ethanol fermentation. BioMed Research International. 2012;2012

[24] Clancy-Hepturn M. Agricultural residues: A promising alternative to virgin wood fiber. Issue in Resources Conservation, Briefing Series. 1998(1)

[25] Ralph J, Lundquist K, Brunow G, Lu F, Kim H, Schatz PF, Marita JM, Hatfield RD, Ralph SA, Christensen JH, Boerjan W. Lignins: Natural polymers from oxidative coupling of 4-hydroxyphenyl-propanoids. Phytochemistry Reviews. 2004;3(1-2):29-60

[26] Laurichesse S, Avérous L. Chemical modification of lignins: Towards biobased polymers. Progress in Polymer Science. 2014;39(7):1266-1290

[27] Hu TQ, editor. Chemical Modification, Properties, and Usage of Lignin. New York: Kluwer Academic/Plenum Publishers; 2002

[28] Vázquez G, Antorrena G, González J, Freire S. The influence of pulping conditions on the structure of acetosolv eucalyptus lignins. Journal of Wood Chemistry and Technology. 1997;17(1-2):147-162

[29] Crestini C, Pastorini A, Tagliatesta P. The immobilized porphyrin-mediator system Mn (TMePyP)/clay/HBT (clay-PMS): A lignin peroxidase biomimetic catalyst in the oxidation of lignin and lignin model compounds. European Journal of Inorganic Chemistry. 2004; 2004(22):4477-4483

[30] Dong A, Fan X, Wang Q, Yu Y, Wang P, Yuan J, Cavaco-Paulo A. Changes on content, structure and surface distribution of lignin in jute fibers after laccase treatment. Journal of Natural Fibers. 2017:1-2

[31] Shioya T, Akiyama T, Yokoyama T, Matsumoto Y. Formation rate of benzyl cation intermediate from p-hydroxyphenyl, guaiacyl, or syringyl nucleus in acidolysis of lignin. Journal of Wood Chemistry and Technology. 2017;37(2):75-86

[32] Montgomery JR, Lancefield CS, Miles-Barrett DM, Ackermann K, Bode BE, Westwood NJ, Lebl T. Fractionation and DOSY NMR as analytical tools: From model polymers to a technical lignin. ACS Omega. 2017;2(11):8466-8474 
[33] Perazzini R, Saladino R, Guazzaroni M, Crestini C. A novel and efficient oxidative functionalization of lignin by layer-by-layer immobilised Horseradish peroxidase. Bioorganic \& Medicinal Chemistry. 2011;19(1):440-447

[34] Lora JH, Glasser WG. Recent industrial applications of lignin: A sustainable alternative to nonrenewable materials. Journal of Polymers and the Environment. 2002;10(1):39-48

[35] Huijgen WJ, Telysheva G, Arshanitsa A, Gosselink RJ, De Wild PJ. Characteristics of wheat straw lignins from ethanol-based organosolv treatment. Industrial Crops and Products. 2014;59:85-95

[36] Ugartondo V, Mitjans M, Vinardell MP. Comparative antioxidant and cytotoxic effects of lignins from different sources. Bioresource Technology. 2008;99(14):6683-6687

[37] Sakagami H, Hashimoto K, Suzuki F, Ogiwara T, Satoh K, Ito H, Hatano T, Takashi Y, Fujisawa SI. Molecular requirements of lignin-carbohydrate complexes for expression of unique biological activities. Phytochemistry. 2005;66(17):2108-2120

[38] KoŠíková B, Lábaj J, Gregorová A, Slameňová D. Lignin antioxidants for preventing oxidation damage of DNA and for stabilizing polymeric composites. Holzforschung. 2006;60(2):166-170

[39] Dizhbite T, Telysheva G, Jurkjane V, Viesturs U. Characterization of the radical scavenging activity of lignins—natural antioxidants. Bioresource Technology. 2004;95(3):309-317

[40] Delmas GH, Benjelloun-Mlayah B, Bigot YL, Delmas M. Functionality of wheat straw lignin extracted in organic acid media. Journal of Applied Polymer Science. 2011;121(1): 491-501

[41] Gosselink RJ, van Dam JE, de Jong E, Scott EL, Sanders JP, Li J, Gellerstedt G. Fractionation, analysis, and PCA modeling of properties of four technical lignins for prediction of their application potential in binders. Holzforschung. 2010;64(2):193-200

[42] Ropponen J, Räsänen L, Rovio S, Ohra-aho T, Liitiä T, Mikkonen H, van de Pas D, Tamminen T. Solvent extraction as a means of preparing homogeneous lignin fractions. Holzforschung. 2011;65(4):543-549

[43] Arshanitsa A, Ponomarenko J, Dizhbite T, Andersone A, Gosselink RJ, van der Putten J, Lauberts M, Telysheva G. Fractionation of technical lignins as a tool for improvement of their antioxidant properties. Journal of Analytical and Applied Pyrolysis. 2013;103:78-85

[44] De Wild PJ, Huijgen WJ, Gosselink RJ. Lignin pyrolysis for profitable lignocellulosic biorefineries. Biofuels, Bioproducts and Biorefining. 2014;8(5):645-657

[45] Vanholme R, Demedts B, Morreel K, Ralph J, Boerjan W. Lignin biosynthesis and structure. Plant Physiology. 2010;153(3):895-905

[46] Neutelings G. Lignin variability in plant cell walls: Contribution of new models. Plant Science. 2011;181(4):379-386

[47] Argyropoulos DS. U.S. Patent No. 9,340,426. Washington, DC: U.S. Patent and Trademark Office; 2016 
[48] Vishtal AG, Kraslawski A. Challenges in industrial applications of technical lignins. BioResources. 2011;6(3):3547-3568

[49] Zakzeski J, Jongerius AL, Bruijnincx PC, Weckhuysen BM. Catalytic lignin valorization process for the production of aromatic chemicals and hydrogen. ChemSusChem. 2012; 5(8):1602-1609

[50] Piazza GJ, Lora JH, Garcia RA. Flocculation of high purity wheat straw soda lignin. Bioresource Technology. 2014;152:548-551

[51] Horáček J, Homola F, Kubičková I, Kubička D. Lignin to liquids over sulfided catalysts. Catalysis Today. 2012;179(1):191-198

[52] Vinardell MP, Ugartondo V, Mitjans M. Potential applications of antioxidant lignins from different sources. Industrial Crops and Products. 2008;27(2):220-223

[53] Mitjans M, Vinardell MP. Biological activity and health benefits of lignans and lignins. Trends in Comparative Biochemistry \& Physiology. 2005;11:55-62

[54] Tay CH, Pugh BT, Clough SR, Magee BH. Dermal irritation assessment of three benzene sulfonate compounds. International Journal of Toxicology. 2004;23(1):11-16

[55] Baurhoo B, Letellier A, Zhao X, Ruiz-Feria CA. Cecal populations of lactobacilli and bifidobacteria and Escherichia coli populations after in vivo Escherichia coli challenge in birds fed diets with purified lignin or mannanoligosaccharides. Poultry Science. 2007; 86(12):2509-2516

[56] Nandi S, Maurer JJ, Hofacre C, Summers AO. Gram-positive bacteria are a major reservoir of Class 1 antibiotic resistance integrons in poultry litter. Proceedings of the National Academy of Sciences of the United States of America. 2004;101(18):7118-7122

[57] Kumor LW, Olkowski AA, Gomis SM, Allan BJ. Cellulitis in broiler chickens: Epidemiological trends, meat hygiene, and possible human health implications. Avian Diseases. 1998;42:285-291

[58] Lee KW. Essential oils in broiler nutrition [doctoral dissertation]. Uttercht University; 2002

[59] Bozin B, Mimica-Dukic N, Simin N, Anackov G. Characterization of the volatile composition of essential oils of some Lamiaceae spices and the antimicrobial and antioxidant activities of the entire oils. Journal of Agricultural and Food Chemistry. 2006;54(5):1822-1828

[60] Oussalah M, Caillet S, Lacroix M. Mechanism of action of Spanish oregano, Chinese cinnamon, and savory essential oils against cell membranes and walls of Escherichia coli O157: H7 and Listeria monocytogenes. Journal of Food Protection. 2006;69(5):1046-1055

[61] Dong X, Dong M, Lu Y, Turley A, Jin T, Wu C. Antimicrobial and antioxidant activities of lignin from residue of corn stover to ethanol production. Industrial Crops and Products. 2011;34(3):1629-1634

[62] Wu C, Chen F, Wang X, Kim HJ, He GQ, Haley-Zitlin V, Huang G. Antioxidant constituents in feverfew (Tanacetum parthenium) extract and their chromatographic quantification. Food Chemistry. 2006;96(2):220-227 
[63] Farrell AE, Plevin RJ, Turner BT, Jones AD, O'hare M, Kammen DM. Ethanol can contribute to energy and environmental goals. Science. 2006;311(5760):506-508

[64] Lau MW, Dale BE. Cellulosic ethanol production from AFEX-treated corn stover using Saccharomyces cerevisiae 424A (LNH-ST). Proceedings of the National Academy of Sciences. 2009;106(5):1368-1373

[65] Abajo C, Boffill MÁ, del Campo J, Méndez MA, González Y, Mitjans M, Vinardell MP. In vitro study of the antioxidant and immunomodulatory activity of aqueous infusion of Bidens pilosa. Journal of Ethnopharmacology. 2004;93(2):319-323

[66] Miki M, Tamai H, Mino M, Yamamoto Y, Niki E. Free-radical chain oxidation of rat red blood cells by molecular oxygen and its inhibition by $\alpha$-tocopherol. Archives of Biochemistry and Biophysics. 1987;258(2):373-380

[67] Pan X, Kadla JF, Ehara K, Gilkes N, Saddler JN. Organosolv ethanol lignin from hybrid poplar as a radical scavenger: Relationship between lignin structure, extraction conditions, and antioxidant activity. Journal of Agricultural and Food Chemistry. 2006;54(16): 5806-5813

[68] Thakur VK, Thakur MK. Recent advances in green hydrogels from lignin: A review. International Journal of Biological Macromolecules. 2015;72:834-847

[69] Davin LB, Lewis NG. Lignin primary structures and dirigent sites. Current Opinion in Biotechnology. 2005;16(4):407-415

[70] Samal SK, Fernandes EG, Corti A, Chiellini E. Hybrid polymeric composites based on polyethylene and lignin. International Journal of Materials and Product Technology. 2009; 36(1-4):62-72

[71] Domenek S, Louaifi A, Guinault A, Baumberger S. Potential of lignins as antioxidant additive in active biodegradable packaging materials. Journal of Polymers and the Environment. 2013;21(3):692-701

[72] Berlinet C, Ducruet V, Brillouet JM, Reynes M, Brat P. Evolution of aroma compounds from orange juice stored in polyethylene terephthalate (PET). Food Additives and Contaminants. 2005;22(2):185-195

[73] Van Bree I, De Meulenaer B, Samapundo S, Vermeulen A, Ragaert P, Maes KC, De Baets $\mathrm{B}$, Devlieghere F. Predicting the headspace oxygen level due to oxygen permeation across multilayer polymer packaging materials: A practical software simulation tool. Innovative Food Science \& Emerging Technologies. 2010;11(3):511-519

[74] Antunez PD, Botero Omary M, Rosentrater KA, Pascall M, Winstone L. Effect of an oxygen scavenger on the stability of preservative-free flour tortillas. Journal of Food Science. 2012;77(1)

[75] Hwang SW, Shim JK, Selke SE, Soto-Valdez H, Matuana L, Rubino M, Auras R. Poly(Llactic acid) with added $\alpha$-tocopherol and resveratrol: Optical, physical, thermal and mechanical properties. Polymer International. 2012;61(3):418-425 
[76] Ouyang W, Huang Y, Luo H, Wang D. Poly(lactic acid) blended with cellulolytic enzyme lignin: Mechanical and thermal properties and morphology evaluation. Journal of Polymers and the Environment. 2012;20(1):1-9

[77] Arvanitoyannis IS, Bosnea L. Migration of substances from food packaging materials to foods. Critical Reviews in Food Science and Nutrition. 2004;44(2):63-76

[78] Blois MS. Antioxidant determination by the use of a stable free radical. Nature. 1958;181: 1199-1200

[79] Sanchez L, Mitjans M, Infante MR, Vinardell MP. Assessment of the potential skin irritation of lysine-derivative anionic surfactants using mouse fibroblasts and human keratinocytes as an alternative to animal testing. Pharmaceutical Research. 2004;21(9): 1637-1641

[80] Ugartondo V, Mitjans M, Lozano C, Torres JL, Vinardell MP. Comparative study of the cytotoxicity induced by antioxidant epicatechin conjugates obtained from grape. Journal of Agricultural and Food Chemistry. 2006;54(18):6945-6950 
